\title{
Study of Pellets and Lumps as Raw Materials in Silicon Production from Quartz and Silicon Carbide
}

\author{
E. DAL MARTELLO, G. TRANELL, S. GAAL, O.S. RAANESS, K. TANG, \\ and L. ARNBERG
}

\begin{abstract}
The use of high-purity carbon and quartz raw materials reduces the need for comprehensive refining steps after the silicon has been produced carbothermically in the electric reduction furnace. The current work aims at comparing the reaction mechanisms and kinetics occurring in the inner part of the reduction furnace when pellets or lumpy charge is used, as well as the effect of the raw material mix. Laboratory-scale carbothermic reduction experiments have been carried out in an induction furnace. High-purity silicon carbide and two different high-purity hydrothermal quartzes were charged as raw materials at different molar ratios. The charge was in the form of lumps (size, 2-5 mm) or as powder (size, 10-20 $\mu \mathrm{m}$ ), mixed and agglomerated as pellets (size, $1-3 \mathrm{~mm})$ and reacted at $2273 \mathrm{~K}\left(2000^{\circ} \mathrm{C}\right)$. The thermal properties of the quartzes were measured also by heating a small piece of quartz in $\mathrm{CO}$ atmosphere. The investigated quartzes have different reactivity in reducing atmosphere. The carbothermal reduction experiments show differences in the reacted charge between pellets and lumps as charge material. Solid-gas reactions take place from the inside of the pellets porosity, whereas reactions in lumps occur topochemically. Silicon in pellets is produced mainly in the rim zone. Larger volumes of silicon have been found when using lumpy charge. More $\mathrm{SiO}$ is produced when using pellets than for lumpy $\mathrm{SiO}_{2}$ for the same molar ratio and heating conditions. The two $\mathrm{SiC}$ polytypes used in the carbothermal reduction experiments as carbon reductants presented different reactivity.
\end{abstract}

DOI: $10.1007 / \mathrm{s} 11663-011-9529-\mathrm{y}$

(C) The Author(s) 2011. This article is published with open access at Springerlink.com

\section{INTRODUCTION}

Metallurgical silicon is produced by the reduction of silica in an electric arc furnace by means of carbonaceous materials. As alternatives to the dominating Siemens chemical route, two main direct metallurgical routes have been established for the production of low-cost solar grade silicon in Norway: the Elkem route (developed by Elkem Solar ${ }^{[1]}$ ) and the Solsilc route (developed by Fesil Sunergy ${ }^{[2]}$ ). The Solsilc route uses high-purity raw materials in form of pellets. It aims at "direct" high-purity silicon production, avoiding several downstream refining steps. Elkem produces a high-grade MG-Si, which is subsequently refined using pyrometallurgical and hydrometallurgical processes.

For both routes, the raw materials play an important role for the optimization of the process. The main quartz specifications are the purity chemistry, lump size, lump mechanical and thermal strength, and softening properties. The absence of fines (particles less than $2 \mathrm{~mm}$ in size) and a softening temperature close to the quartz melting point are desirable to maintain a high gas

E. DAL MARTELLO, Ph.D. Student, G. TRANELL, Professor, and L. ARNBERG, Research Scientist, are with the NTNU Department of Materials Science and Engineering, 7491 Trondheim, Norway. Contact e-mail: dalmarte@material.ntnu.no S. GAAL, O.S. RAANESS, and K.TANG, Research Scientists, are with the SINTEF Materials and Chemistry, 7465 Trondheim, Norway.

Manuscript submitted February 26, 2011.

Article published online May 20, 2011. permeability in the furnace burden ${ }^{[3]}$ Common impurities in quartz, like $\mathrm{Na}, \mathrm{K}, \mathrm{Al}$, and $\mathrm{Fe}$, come from minerals like mica and feldspar. Hydrothermal quartz and pegmatite core are the purest among the silica sources.

These can be purified even more by means of mineral liberation, separations, and acid treatments. ${ }^{[4,5]}$ The purification processes must be carried out with fine particles (in the range of micrometers). To charge these materials in an electric arc furnace, agglomeration (pellets or briquettes) is necessary.

$\mathrm{SiO}$ reactivity ${ }^{\left[{ }^{[6}\right.}$ and chemistry are the most important distinguishing properties of carbon. High-reactivity carbon materials are desirable as reductants, because they preserve matter and energy in the process by rapidly reacting with energy-rich $\mathrm{SiO}(\mathrm{g})$. The $\mathrm{SiO}$ reactivity of coal based reductants depends mainly on the ranks of the coals, on its petrographic properties, ${ }^{[7]}$ on the carbon particle size and on the $\mathrm{SiO}$ diffusion in pores. ${ }^{[8]}$ Coal and charcoal contain both $\mathrm{B}, \mathrm{P}$, and ash minerals mainly consisting of $\mathrm{SiO}_{2}, \mathrm{Fe}_{2} \mathrm{O}_{3}, \mathrm{Al}_{2} \mathrm{O}_{3}, \mathrm{TiO}_{2}$, $\mathrm{CaO}$, and $\mathrm{MgO}$. $\mathrm{B}$ and $\mathrm{P}$ originate from the plants, whereas ash containing oxides derive from clay minerals deposited onto the plant material precursors. ${ }^{[9]}$ Highpurity carbon black is a synthetic carbonaceous powder material produced from pure liquefied natural gas or methane. Low B and P content in the metal produced is necessary because these elements are difficult to remove by directional solidification in the subsequent ingot production of silicon for photovoltaic purposes. 
In the submerged arc furnace, silicon and carbon raw materials react under atmospheric pressure over a range temperature of $1573 \mathrm{~K}$ to $2273 \mathrm{~K}\left(1300{ }^{\circ} \mathrm{C}\right.$ to $\left.2000{ }^{\circ} \mathrm{C}\right)$. The upper low temperature part of the furnace is called the outer zone, whereas the hottest part of the furnace the inner zone. There is general agreement about the reactions taking place in the inner zone of the furnace. ${ }^{[6,10-13]}$ The main reactions in the inner zone are as follows:

$$
\begin{gathered}
2 \mathrm{SiO}_{2(\mathrm{l})}+\mathrm{SiC}_{(\mathrm{s})}=3 \mathrm{SiO}_{(\mathrm{g})}+\mathrm{CO}_{(\mathrm{g})} \\
\mathrm{SiO}_{(\mathrm{g})}+\mathrm{SiC}_{(\mathrm{s})}=2 \mathrm{Si}_{(\mathrm{l})}+\mathrm{CO}_{(\mathrm{g})} \\
\mathrm{Si}_{(\mathrm{l})}+\mathrm{SiO}_{2(\mathrm{l})}=2 \mathrm{SiO}_{(\mathrm{g})}
\end{gathered}
$$

The prevailing gaseous species in the furnace are $\mathrm{SiO}(\mathrm{g})$ and $\mathrm{CO}(\mathrm{g})$. In the inner crater zone silicon carbide and molten silica react with each other and form $\mathrm{SiO}(\mathrm{g})$, $\mathrm{CO}(\mathrm{g})$, and $\mathrm{Si}$ according to Eqs. [1] and [3]. In the outer zone of the furnace, carbon reacts with the ascending $\mathrm{SiO}$ and $\mathrm{CO} \cdot{ }^{[14,15]} \mathrm{SiO}(\mathrm{g})$ produced in the inner zone is recovered in the outer zone through condensation to $\mathrm{Si}$ and $\mathrm{SiO}_{2}$ and through the reaction with $\mathrm{C}$ to form $\mathrm{SiC}$. Equation [4] is the overall reaction for the inner zone under equilibrium condition at $1 \mathrm{~atm}\left(10^{5} \mathrm{~Pa}\right) .^{[6,14,15]}$

$$
3 \mathrm{SiO}_{2}+2 \mathrm{SiC}=\mathrm{Si}+4 \mathrm{SiO}_{(\mathrm{g})}+2 \mathrm{CO}_{(\mathrm{g})}
$$

Equation [5] represents the overall reaction for the inner zone under nonequilibrium conditions when $\mathrm{P}_{\mathrm{SiO}}=0.5$ and the temperature is about $2253 \mathrm{~K}$ $\left(1980{ }^{\circ} \mathrm{C}\right) .{ }^{[14,16]}$

$$
\mathrm{SiO}_{2(1)}+\mathrm{SiC}_{(\mathrm{s})}=\mathrm{Si}_{(1)}+\mathrm{SiO}_{(\mathrm{g})}+\mathrm{CO}_{(\mathrm{g})}
$$

$\mathrm{SiO}$ is formed at lower temperatures at the silica-gas interface by the reaction ${ }^{[12,15,17-19]}$

$$
\mathrm{SiO}_{2(\mathrm{~s}, \mathrm{l})}+\mathrm{CO}_{(\mathrm{g})}=\mathrm{SiO}_{(\mathrm{g})}+\mathrm{CO}_{2(\mathrm{~g})}
$$

According to $\mathrm{Wiik}^{[12]}$ and Sahajwalla et al. ${ }^{[18]} \mathrm{SiO}$ can also be generated at the $\mathrm{SiC}$-gas interface at higher temperatures. In absence of free carbon, $\mathrm{SiC}$ may take over the role of carbon and react with $\mathrm{CO}_{2}(\mathrm{~g})$ to form $\mathrm{SiO}(\mathrm{g})$ and $\mathrm{CO}(\mathrm{g})$.

$$
2 \mathrm{CO}_{2(\mathrm{~g})}+\mathrm{SiC}=\mathrm{SiO}_{(\mathrm{g})}+3 \mathrm{CO}_{(\mathrm{g})}
$$

Danes et $a l .{ }^{[13]}$ carried out a thermodynamic study of the $\mathrm{Si}-\mathrm{C}-\mathrm{O}$ system in an isobaric reactor. The reactor was first filled with inert gas at 1 atm and the pressure was held constant by means of a regulating valve which allowed gas evacuation. When an initial complex of $\mathrm{SiC}+\mathrm{SiO}_{2}$ is heated, $\mathrm{SiO}+\mathrm{CO}$ pressure increases until it reaches $1 \mathrm{~atm}\left(10^{5} \mathrm{~Pa}\right)$. This condition represents the invariant points where three condensed phases $(\mathrm{Si}, \mathrm{SiC}$, and $\mathrm{SiO}_{2}$ ) are in equilibrium at the specific temperature $2104 \mathrm{~K}\left(1811^{\circ} \mathrm{C}\right)$ and gas composition. The reaction [1] runs at constant temperature until either $\mathrm{SiC}$ or $\mathrm{SiO}_{2}$ is consumed. Above $2104 \mathrm{~K}\left(1811^{\circ} \mathrm{C}\right)$ depending on the progress of the reactions [2] and [3], $\mathrm{Si}, \mathrm{SiC}+\mathrm{Si}$, or $\mathrm{Si}+\mathrm{SiO}_{2}$ will not be consumed completely.
Hirasawa $^{[11]}$ produced silicon in a two-stage reduction process. It was observed that more silicon was formed at $2273 \mathrm{~K}\left(2000{ }^{\circ} \mathrm{C}\right)$ than at $2223 \mathrm{~K}\left(1950{ }^{\circ} \mathrm{C}\right)$, and that a larger amount of $\mathrm{Si}$ was obtained for longer holding time at $2273 \mathrm{~K}\left(2000{ }^{\circ} \mathrm{C}\right)$. They found that the reduction of $\mathrm{SiO}_{2}$ into $\mathrm{SiO}(\mathrm{g})$ (reaction [1]) is the reaction ratecontrolling step.

Fruehan and Ozturk ${ }^{[17]}$ and Wiik ${ }^{[12]}$ studied the rate of formation of $\mathrm{SiO}(\mathrm{g})$ by reacting $\mathrm{CO}(\mathrm{g})$ with silica (reaction [6]). Experimental observations strongly indicated that the rate of formation of $\mathrm{SiO}(\mathrm{g})$ is controlled by chemical kinetics on the silica surface.

$\mathrm{SiC}$ occurs in different polytypes. According to the JANAF Thermochemical Tables, ${ }^{[20]}$ the cubic polytype $(\beta-\mathrm{SiC})$ is more stable than the hexagonal $(\alpha-\mathrm{SiC})$ at all temperatures, but the difference is so small that is not important in the equilibrium evaluation of the system. Filsinger and Bourrie ${ }^{[10]}$ and Presser and Nickel ${ }^{[21]}$ stated that the reactivity of silica with $\mathrm{SiC}$ does not depend on the crystal structure of the SiC.

The solid-state reactivity and the surface structure of quartz changes when the surface is activated mechanically. ${ }^{[2-25]}$ During the mechanical treatment of quartz (grinding or milling), Si-O bonds are broken and highly disordered silica layers (thickness from 20 to $500 \mathrm{~nm}$ ) are formed on the surface of the quartz grains. ${ }^{[24]}$ These deviations from ideal lattice are metastable defects that lead to the storage of energy and increase the reactivity of the material. According to Steinike and Tkáčová, [23] mechanically activated quartz shows an increase in the extent of adsorption and gas diffusion into the disturbed near surface layers. Quartz seems more reactive with $\mathrm{CO}_{2}(\mathrm{~g})$ than $\mathrm{O}_{2}(\mathrm{~g})$. They also observed that mechanically activated quartz (low temperature form) transforms directly into crystobalite at a temperature of $1473 \mathrm{~K}$ $\left(1200{ }^{\circ} \mathrm{C}\right)$, which is lower than the high-temperature quartz-crystobalite transformation at approximately $1673 \mathrm{~K}\left(1400^{\circ} \mathrm{C}\right)$. This was confirmed by Balek et al. ${ }^{[24]}$

Agarwal and Pad ${ }^{[26]}$ used thermogravimetry to study the kinetics of reactions in pellets, which were made of carbon black and silica. The reaction rate increases by reducing both carbon and silica particle size, but no significant improvement occurs below a critical size of $20 \mu \mathrm{m}$. In general, in a powder compact, where the reaction occurs between solids through gaseous intermediates, the possible reaction controlling steps can be surface reactions or diffusion of the gases through the pores or a combination of these. When pellets made of carbon and silica mixture are heated, they react quickly to $\mathrm{SiO}(\mathrm{g})$ and $\mathrm{CO}(\mathrm{g})$. When $\left(\mathrm{P}_{\mathrm{CO}} /\left(\mathrm{P}_{\mathrm{CO}}+\mathrm{P}_{\mathrm{SiO}}\right)\right)$ reaches the chemical equilibrium value, the reaction retards quickly. $\mathrm{CO}(\mathrm{g})$ has to diffuse out of the pellet for subsequent reaction taking place. Agarwal and Pad state that pellets porosity leads to higher rates of diffusions of $\mathrm{CO}(\mathrm{g})$ and $\mathrm{SiO}(\mathrm{g})$ from pellets and, therefore, an increase in reaction rate for the reduction of $\mathrm{SiO}_{2}$ to $\mathrm{SiO}(\mathrm{g})$.

Jensen $^{[27]}$ recorded the reactions taking place in the crater zone of a $50-\mathrm{kW}$ single electrode pilot scale furnace when lumpy charge was used. From the images, the crater appears complex and dynamic. $\mathrm{SiO}_{2}$ reacts with $\mathrm{SiC}$ and forms $\mathrm{Si}(1), \mathrm{SiO}(\mathrm{g})$, and $\mathrm{CO}$. The cavity 
expands as the reaction proceeds. The expansion of the cavity is balanced by $\mathrm{SiO}_{2}$ and $\mathrm{SiC}$ entering slowly the crater. Melted viscous quartz enters in the crater zone slowly. $\mathrm{SiC}$ is still a solid phase and is covered by a thin Si layer. A Si bath is present on the bottom; $\mathrm{SiC}$ pieces and melted quartz float into it. When quartz enters in contact with $\mathrm{SiC}$, it reacts violently starting bubbling and $\mathrm{SiO}(\mathrm{g})$ is produced according to reaction [1]. When $\mathrm{SiC}$ enters in the crater zone it disappears fast according to reaction [2]. When $\mathrm{Si}$ and $\mathrm{SiO}_{2}$ enter in contact, $\mathrm{SiO}_{2}$ starts bubbling and the reactants quickly disappear according to reaction [3].

Although there have been some theoretical suggestions ${ }^{[13,15]}$ and experimental attempts ${ }^{[11,12,17,28]}$ to produce silicon on small scale, no experiment has successfully reproduced the inner zone environment of the industrial furnace. There have also been investigations on the reactivity of lumpy silica ${ }^{[12,17,28]}$ and pellets. ${ }^{[26]}$ However, these studies were not performed under the conditions of silicon production and did not attempt to compare the reaction mechanisms and kinetics of the same raw materials used either as lumpy or pellet charge.

The aim of the present investigation was therefore:

(a) To develop a small-scale experimental setup that can adequately simulate the hot zone of the industrial silicon production furnace

(b) To study the mechanisms and kinetics of the reactions between quartz and $\mathrm{SiC}$ when the two compounds are present as fine powder in pellets or as lumps in different charge mixes

\section{MATERIALS AND METHODS}

\section{A. Materials}

The charge materials were in the form of lumps or pellets. Two high-purity hydrothermal quartzes, denoted quartz A and quartz B, and one source of highpurity $\mathrm{SiC}$ have been used as charge materials. Quartz A has been used previously for production of SoG-Si, whereas the second quartz type, quartz $\mathrm{B}$, comes from another deposit showing promise as raw material for SoG-Si production. The quartz structures were investigated by optical microscopy. Micrographs of the samples are shown in Figure 1. Quartz A, Figure 1(a), has big grains of 3-4 mm size and plenty of fluid inclusions. The square shape and the size of the grains indicate that the quartz has a geological history of metamorphism without strain. The grain boundaries have been investigated under fluorescent microscopy and appear to be relatively dense. Quartz B, Figure 1(b), is characterized by smaller grains and less fluid inclusions. The size of the grains and the interlocked grain boundaries indicate that this quartz has been subjected to recrystallization, strain, and distortion processes. The grain boundaries are open and interconnected. The $\mathrm{SiC}$ used as charge is a mixture of hexagonal (6H:SiC) and rhombohedral (15R:SiC) polytypes; no cubic $\mathrm{SiC}(3 \mathrm{C}: \mathrm{SiC})$ is present. The number indicates the number of layers in the stacking sequence, the letter the class: H, R, C stands for hexagonal, rhombohedral, and cubic, respectively. According to another designation, hexagonal and rhombohedral polytypes can be denoted as $\alpha$ type, whereas cubic polytype as $\beta$ type. ${ }^{[29]}$

Lumps of size $3-5 \mathrm{~mm}$ and pellets of $1-2 \mathrm{~mm}$ diameter were used. The total weight of the charge was $25 \mathrm{~g}$ when pellets were used and $18 \mathrm{~g}$ for the case of lumpy charge. Pellets consist of a mixture of quartz and silicon carbide powder. The powder was produced by milling the quartz up to $20 \mu \mathrm{m}$ and the $\mathrm{SiC}$ up to $10 \mu \mathrm{m}$ size (the values represent the median). The size was chosen following the study by Agarwal and Pal. ${ }^{[26]}$ The two components of the mixture, $\mathrm{SiC}$ and $\mathrm{SiO}_{2}$, were first dry blended together and then delivered into a pelletizing plate $(22 \mathrm{~cm}$ diameter and $24 \mathrm{~cm}$ rim on its outer circumference). Simultaneously with the feeding of the two-component mixture into the pelletizing plate, demineralized water was supplied to enable the formation of micro pellets (1-2 mm diameter). No binding agents have been used. Because pellets contain water, the charge was dried in a graphite crucible at $353 \mathrm{~K}$ $\left(80^{\circ} \mathrm{C}\right)$ for 10 hours prior to the experiments.
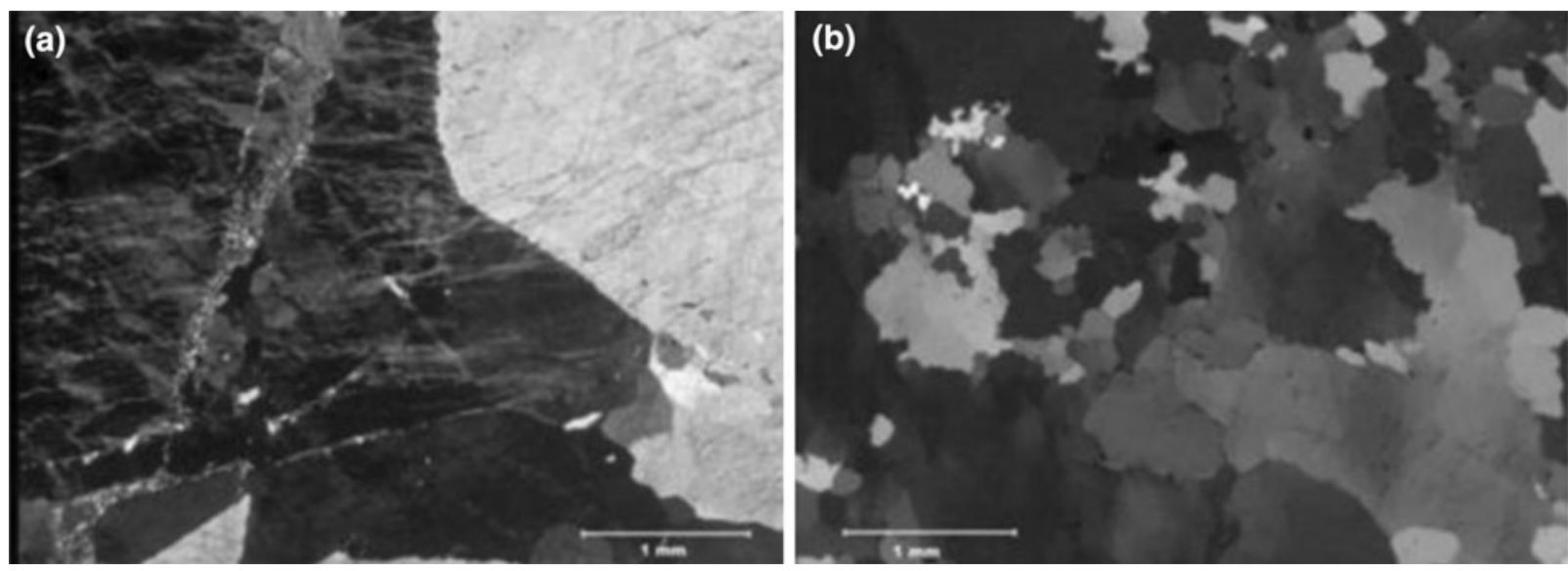

Fig. 1-Micrographs of quartz A (a) and quartz B (b) in cross-polarized light. 


\section{B. Experimental Setup and Procedure}

The following two types of experiments were carried out:

- Carbothermic reduction experiments, where mixtures of $\mathrm{SiC}$ and $\mathrm{SiO}_{2}$ in the form of pellets or lumps were used as charge materials, for the purpose of studying and comparing reaction mechanisms

- In situ melting experiments on small silica pieces, to study their thermal properties

The carbothermic reduction experiments were carried out in a small-scale $6-\mathrm{kW}$ induction furnace setup. Two high-purity graphite crucibles $(7 \mathrm{~cm}$ in diameter and $15 \mathrm{~cm}$ in height) were filled with charge (lumps or pellets). They were then fitted in a bigger graphite crucible as depicted in Figure 2. This configuration allowed running two experiments at the same time under the same conditions. Next, two different quartz sources were run at the same time. Similar to the experiments by Filsinger and Bourrie ${ }^{[10]}$ and Wiik, ${ }^{[12]}$ the crucibles were closed with a loose-fit vented lid to create a $\mathrm{SiO}-\mathrm{CO}$ atmosphere necessary for the silicon production reaction. The graphite crucible has the advantage to withstand high temperatures, to be available in high purity even if it reacts with $\mathrm{SiO}(\mathrm{g})$, and to form $\mathrm{SiC}$ and $\mathrm{Si}$; the amount of $\mathrm{SiC}$ and $\mathrm{Si}$ formed can be quantified. [30]

In an industrial electric furnace, the charge follows different paths in its decent through the furnace, each of the paths with a different retention time. The shortest time from when the raw material is charged until it reaches the crater in an industrial furnace is typically 1-2 hours. ${ }^{[3]}$ A heating profile 80 minutes long was chosen to be representative to the shortest retention time $^{[3]}$ and to reproduce previous silicon production experiments. ${ }^{[11]}$ The heating profile is shown in Figure 3. The charge was heated to $2073 \mathrm{~K}\left(1800^{\circ} \mathrm{C}\right)$ at $90 \mathrm{~K} / \mathrm{min}$, then from $2073 \mathrm{~K}$ to $2273 \mathrm{~K}\left(1800^{\circ} \mathrm{C}\right.$ to $2000{ }^{\circ} \mathrm{C}$ ) at $5 \mathrm{~K} / \mathrm{min}$, and then the temperature was kept constant at $2273 \mathrm{~K}\left(2000{ }^{\circ} \mathrm{C}\right)$ for $20 \mathrm{~min}$. After the

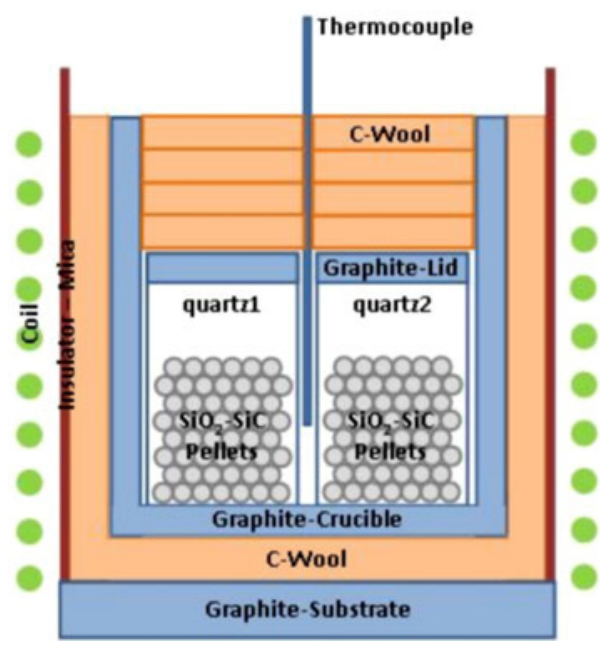

Fig. 2-Experimental setup of carbothermic reduction experiments in an induction furnace. In the figure: pellets as charge material. experiments, the crucible was cooled rapidly (approximately $100 \mathrm{~K} / \mathrm{min}$ ). Type $\mathrm{C}$ tungsten-rhenium thermocouples were placed in the holding crucible between the two reaction crucibles. The temperature outside the crucibles was assumed to be the same as inside the crucible. New thermocouples were used for each experiment because they degraded fast in the high-temperature and $\mathrm{SiO} / \mathrm{CO}$ atmosphere.

A reducing atmosphere was maintained during the whole experiment. The furnace was first evacuated: The calculated oxygen content after evacuation was $\sim 1.2 \times 10^{-6}$ moles $\mathrm{O}_{2}$. The furnace was subsequently filled with argon 5.0 purity at $5.8 \mathrm{mbar}(580 \mathrm{~Pa})$ : The oxygen content carried by the argon filling is $\sim 4 \times 10^{-5}$ moles $\mathrm{O}_{2}$. The oxygen coming from the crucible is assumed negligible because the crucible was preheated to $373 \mathrm{~K}\left(100^{\circ} \mathrm{C}\right)$ overnight. Leakages were measured in a time interval of 10 hours and were found to be negligible for the time needed by the experiment: 0.003 mbar $(0.3 \mathrm{~Pa})$ during the argon filling and 0.0025 mbar $(0.25 \mathrm{~Pa})$ during the experiment. At the beginning of each experiment, the chamber was filled to approximately $0.75 \mathrm{~atm}(75000 \mathrm{~Pa})$ with argon. During heating the pressure inside the chamber increased. The total pressure in the chamber reached approximately 1 atm $\left(10^{5} \mathrm{~Pa}\right)$ at $2273 \mathrm{~K}\left(2000{ }^{\circ} \mathrm{C}\right)$.

The experiments were designed to study three factors during eight runs. The eight-run design was constructed with a full factor standard table of signs (Table I) for varying quartz type, $\mathrm{SiO}_{2}$ to $\mathrm{SiC}$ molar ratio, and charge type.

The total weight of the charge mix was maintained constant for all the experiments; $25 \mathrm{~g}$ and $18 \mathrm{~g}$ have been used for pellets and lumpy charge, respectively. The weight difference is caused by the pelletizing procedure. The pellets were weighed once in the crucible and once dried, and it was not possible to predict the amount of water adsorbed during the pelletizing procedure. Two molar ratios have been investigated. The molar ratio of $\mathrm{SiO}_{2} / \mathrm{SiC}=1 / 2$ refers to the stoichiometry of reactions [1] and [2]. A molar ratio of 1:1 refers to the stoichiometric overall reaction taking place in the inner zone proposed by Schei et al. ${ }^{[14]}$ and Müller. ${ }^{[16]}$ It was decided to start the experiment without liquid $\mathrm{Si}$ bath on the bottom to focus on the reactions between $\mathrm{SiC}$ and $\mathrm{SiO}_{2}$.

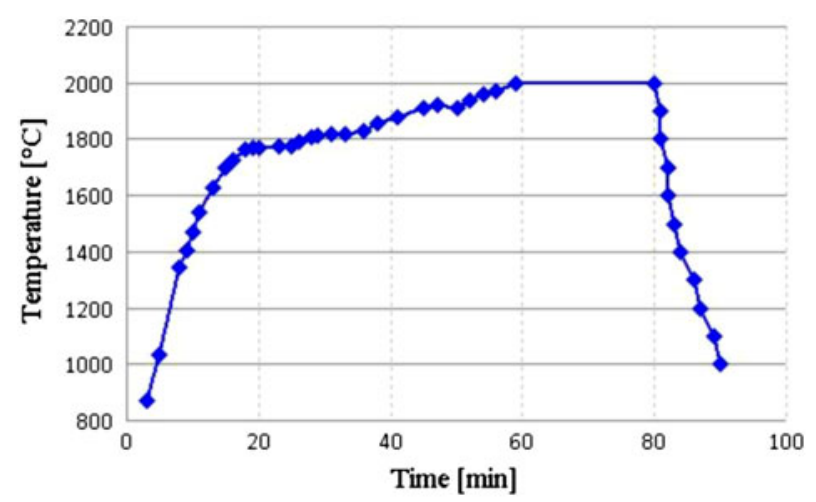

Fig. 3-Heating profile for the carbothermic reduction experiments. 
Table I. Experimental Variables in the Carbothermic Reduction Experiments: Quartz Source, Charge Size, and $\mathrm{SiO}_{2}: \mathrm{SiC}$ Molar Ratio

\begin{tabular}{lllllllll}
\hline Quartz & A & B & A & B & A & B & A & B \\
\hline Charge size & Lumps & Lumps & Lumps & Lumps & Pellets & Pellets & Pellets & Pellets \\
Molar ratio & $1: 2$ & $1: 2$ & $1: 1$ & $1: 1$ & $1: 2$ & $1: 2$ & $1: 1$ & $1: 1$ \\
\hline
\end{tabular}

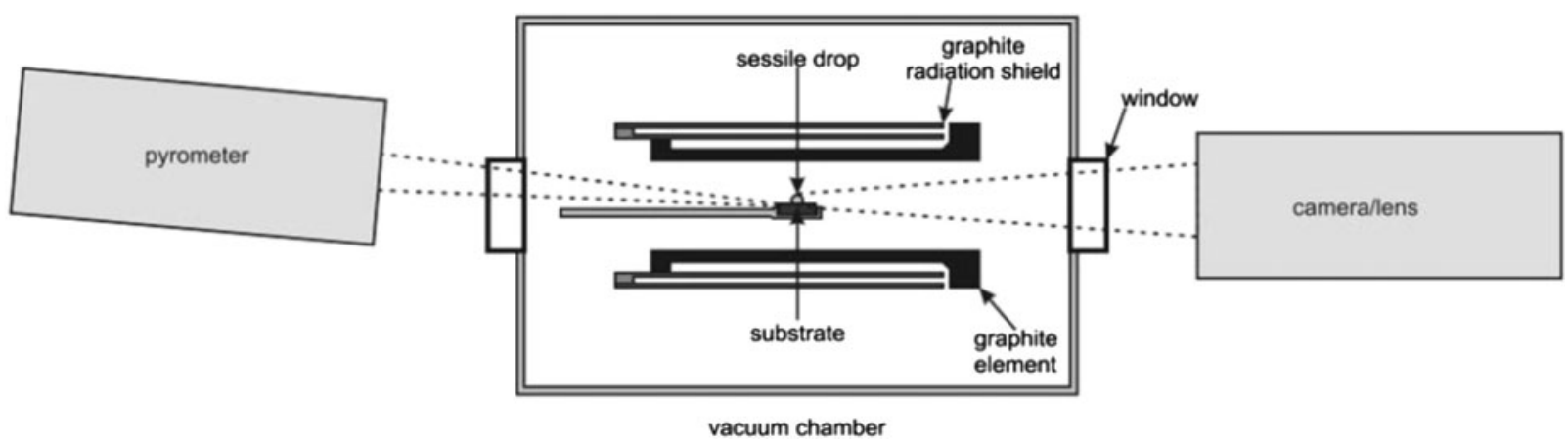

Fig. 4-Experiment in a sessile drop furnace: The furnace records high-temperature properties of quartz. The sample is placed on a substrate and heated. A camera records the sample and a pyrometer measures the temperature of the sample surface during heating.

The second type of experiments aimed at studying the high-temperature properties of lumpy silica. The experiments were run in a sessile drop setup shown in Figure 4. This setup allows us to record high-temperature properties of samples placed on substrate when both atmosphere and heating rates are controlled. The silica samples were placed on a substrate and heated. A camera placed in one end outside the furnace records the sample during heating by taking a picture every second. From this image, the melting temperature and the volume expansion can be estimated. Silica cylindrical samples (Ø $=3 \mathrm{~mm} ; \mathrm{h}=3 \mathrm{~mm})$ have been investigated. Cylindrical samples and drill cores from a 3-mmthick plate cut out of the original quartz sample with a diamond saw were used for these experiments. Seven samples of quartz A and 11 samples of quartz B have been studied. The experiments were run in $\mathrm{CO}$ atmosphere and reaction [6] is expected to take place. Both the melting point and the reactivity, i.e., the $\mathrm{SiO}$ production, of the quartz with $\mathrm{CO}(\mathrm{g})$ have been measured. The samples were placed on a nonreactive glassy carbon substrate and heated to $1173 \mathrm{~K}\left(900{ }^{\circ} \mathrm{C}\right)$ in approximately 3 minutes. From $1173 \mathrm{~K}$ to $1473 \mathrm{~K}$ $\left(900{ }^{\circ} \mathrm{C}\right.$ to $\left.1200{ }^{\circ} \mathrm{C}\right)$, the heating rate was set to $100 \mathrm{~K} / \mathrm{min}$, and from to $1473 \mathrm{~K}$ to $2273 \mathrm{~K}\left(1200{ }^{\circ} \mathrm{C}\right.$ to $2000{ }^{\circ} \mathrm{C}$ ) was set to $20 \mathrm{~K} / \mathrm{min}$. The temperature was measured by a pyrometer calibrated against the melting point of iron. Previously, similar experiments have been performed by Andersen ${ }^{[28]}$ in $\mathrm{CO}$ and $\mathrm{Ar}$ atmosphere using a similar heating rate.

\section{Method for Analysis}

The reaction products of the carbothermic Si production experiments were analyzed both qualitatively and quantitatively. The samples were embedded in epoxy and their microstructure studied in JEOL JXA-8500F electron probe microanalyzer (EPMA) (JEOL Ltd.,
Peabody, CA). Each experiment was repeated three times when lumps were used and two times when pellets were used. The experiments with pellets were repeated only twice because they showed little variability in the weight losses. The representative samples that showed weight losses close to the average value for each experimental condition were analyzed quantitatively. The crucibles and reacted charges were crushed together to a fine powder with $50-\mu \mathrm{m}$ upper size by means of a tungsten carbide vibratory disk mill and analyzed by $\mathrm{X}$-ray diffraction (XRD) and X-ray fluorescent (XRF). D8 Advance XRD (Bruker, Bruker AXS Nordic AB, Solna, Sweden) generator, BRUKER-EVA qualitative, BRUKER-TOPAS quantitative interpreter program, and XRF BRUKER S8 Tiger 4kW X-ray spectrometer have been used. ${ }^{[31]}$ XRF uses a semiquantitative method to estimate the weight percentage of $\mathrm{Si}$, and it does not detect elements such $\mathrm{C}$ and O. XRD quantifies crystalline phases and all their polymorphs. The combination of XRF and XRD techniques make them a valuable tool for quantitative phase analysis. ${ }^{[30]}$ The overall mass balance is presented in Eq. [8]. The phases to the left are input charge material and their amount has been analyzed. The phases to the right are output products and their amount is unknown. $\mathrm{C}$ represents the graphite in the crucible; it has to be included in the mass balance because it participates in the reaction with $\mathrm{SiO}(\mathrm{g})$.

$$
\begin{aligned}
& a \mathrm{SiO}_{2}+b 15 \mathrm{R}: \mathrm{SiC}+c 6 \mathrm{H}: \mathrm{SiC}+d \mathrm{C} \\
& =p \mathrm{Si}+g \mathrm{SiO}_{2}+s 15 \mathrm{R}: \mathrm{SiC}+t 6 \mathrm{H}: \mathrm{SiC} \\
& \quad+u 3 \mathrm{C}: \mathrm{SiC}+z \mathrm{SiO}+x \mathrm{CO}+y \mathrm{C}
\end{aligned}
$$

Experiments in the sessile drop furnace aimed at measuring the temperature of melting and the quartz weight losses (as $\mathrm{SiO}$ ) in $\mathrm{CO}$ atmosphere. It was possible to calculate the weight losses by weighing the silica sample before and after the experiments. The reaction 
rate was determined in terms of $\mathrm{SiO}$ losses. The temperature of melting was determined by the moment the quartz became glassy. When the quartz starts melting, voids are sealed; there is no more light diffraction and the sample turns transparent and glassy. This valid method is used to compare the melting properties of different quartzes, but the melting temperature must not be considered an absolute value because it is influenced by the sample size and by the heating rate. In an industrial furnace, the large quartz lumps subjected to the highest possible heating rate do not usually soften before reaching the hot inner crater zone of the furnace. ${ }^{[28]}$

\section{RESULTS}

\section{A. Silicon Production Experiments}

The carbothermic reduction experiments simulate a complicated system involving reactions between solid,

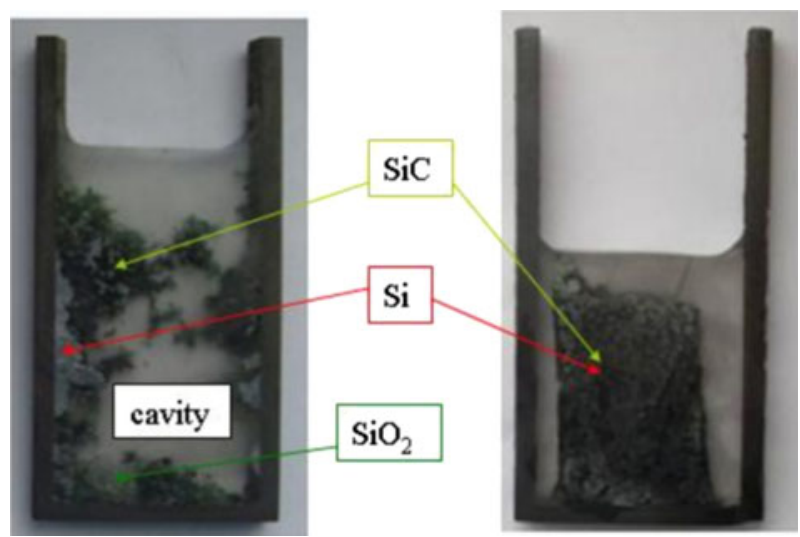

Fig. 5-Reacted charge for different charge size and molar ratio $\mathrm{SiO}_{2}: \mathrm{SiC}=1: 1$. On the left is lumps, and on the right is reacted pellets. liquid, and gaseous phases. Because the duration of the experiment is short, these reactions might not reach equilibrium but the experiments are instead intended to represent the relative rates of the predominant reactions.

Non-reacted quartz, silicon carbide and silicon phases have been found in the crucible after experiments. Figure 5 shows the product morphology of the reacted crucible for the case of lumps (on the left side) and pellets (on the right side). The cross sections of the reacted crucibles looked similar regardless of the type of quartz and molar ratio used. Reacted lumpy charge is shown in Figure 5 on the left side: the structure is loose, a cavity is present, melted quartz and droplets of silicon are found mainly on the bottom of the crucible. Microscope and XRD investigations showed that non-reacted silica was present only as an amorphous (melted) phase. A cavity and large area of single phase silicon metal were also found. Pellets have a different reaction pattern than lumps. The reacted pellet charge is compacted, porous and has low interaction with the crucible. The pellets have shrunk and $\mathrm{Si}$ is found mainly in the bottom of the crucible. It is difficult to recognize the spherical original shape of pellets for the experiments with molar ratio $\mathrm{SiO}_{2}: \mathrm{SiC}=1: 1$. SiC particles decreases in size from a mean diameter of $9.26 \mu \mathrm{m}$ to approximately $5 \mu \mathrm{m}$.

Figure 6 shows the microstructure of the reacted lumps and reacted pellets for molar ratio $\mathrm{SiO}_{2}$ : $\mathrm{SiC}=1: 2$. Figure 6(a) is a SEM backscatter image of reacted $\mathrm{SiC}$ lumps. Silicon, in light grey, has nucleated on the carbide surface. Figure 6(b) shows the microstructure of the reacted pellets where $\mathrm{SiC}$ particles have dark grey and silicon light grey contrast. The original acicular shape of the $\mathrm{SiC}$ particles has become round indicating that carbide has reacted to $\mathrm{Si}, \mathrm{SiO}(\mathrm{g})$ and $\mathrm{CO}(\mathrm{g})$. In both cases silicon nucleates on the $\mathrm{SiC}$ surface without any direct contact with silica, indicating that a solid-solid reaction has not taken place. Almost all of the silica has reacted when pellets have been used. Figure 7 shows a cross-section of the crucible as seen by
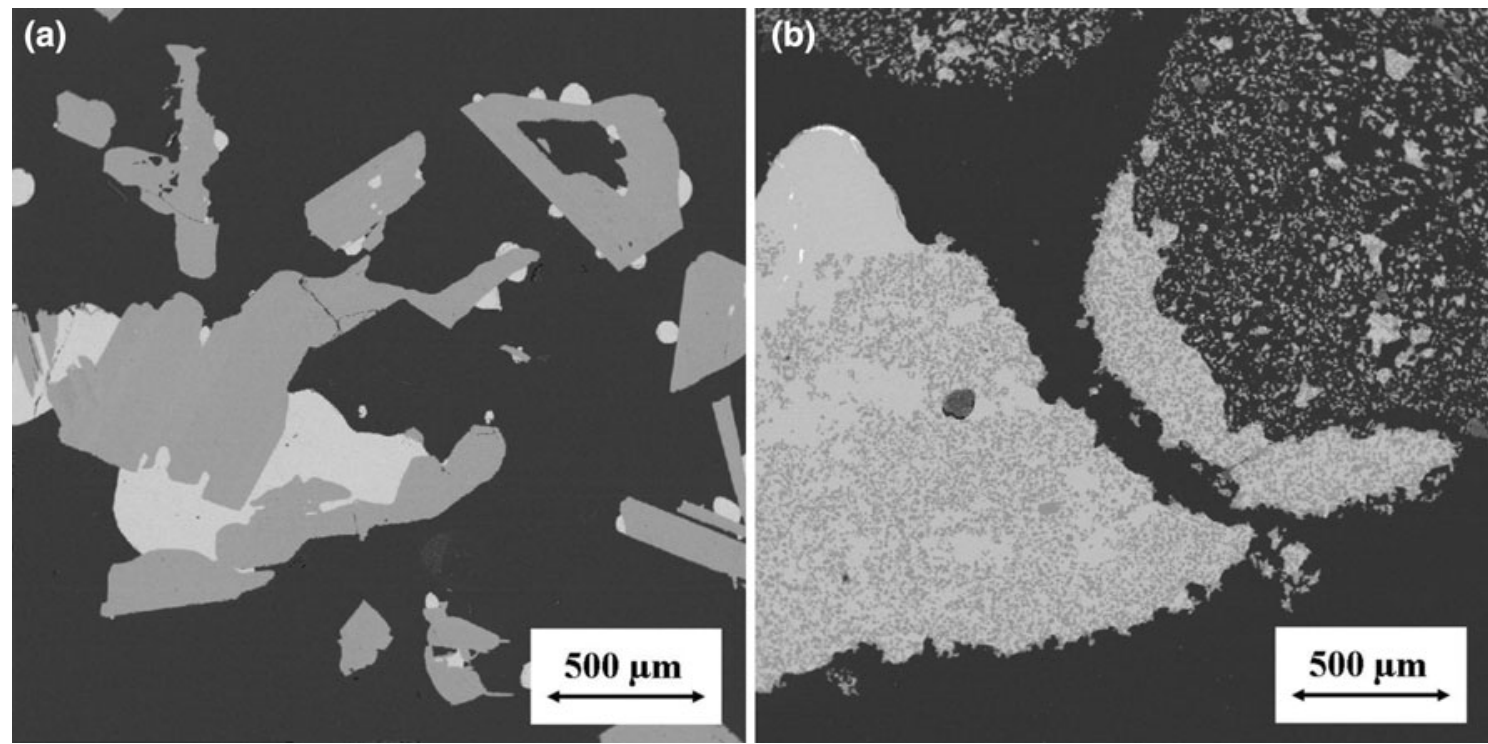

Fig. 6-Backscattering images of reacted charge. (a) Lumps, molar ratio $\mathrm{SiO}_{2}: \mathrm{SiC}=1: 2$. (b) Pellets, molar ratio $\mathrm{SiO}_{2}: \mathrm{SiC}=1: 2$. 

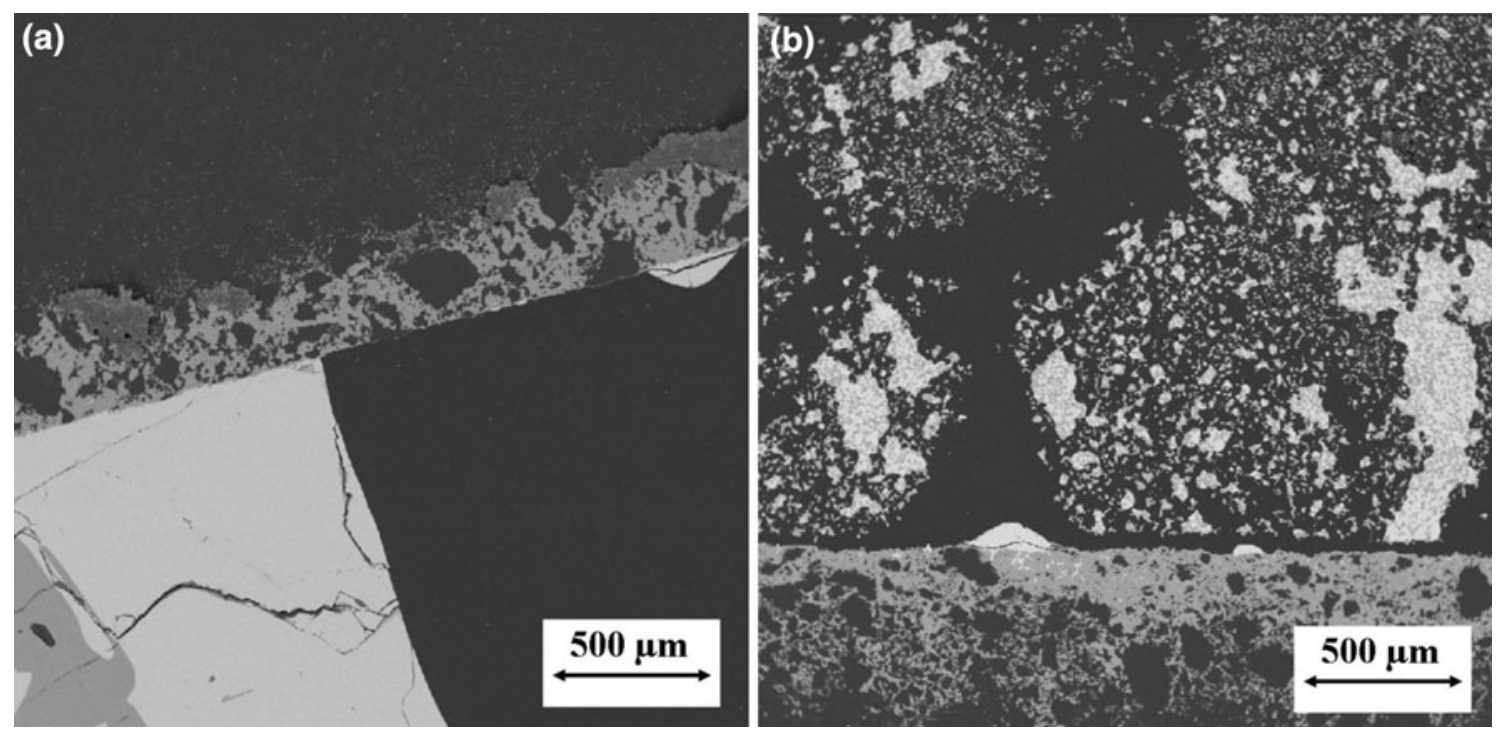

Fig. 7-Backscattering of the reacted crucible: $(a)$ lumps and $(b)$ pellets. The gray rim on the crucible surface is 3C:SiC. Small droplets of silicon on the silicon carbide surface are present in light grey tone. The pictures are at the same magnification.

Table II. Average Total Weight Losses for Different $\mathrm{SiO}_{2}: \mathrm{SiC}$ Molar Ratio and Type Charge*

\begin{tabular}{lllll}
\hline Type & Lumps & Lumps & Pellets & Pellets \\
\hline Ratio & $1: 2$ & $1: 1$ & $1: 2$ & $1: 1$ \\
Losses & 42.1 pct & 58.0 pct & 44.8 pct & 65.8 pct \\
\hline
\end{tabular}

*The variance in the process is 2.5 pct. It has been calculated over all the experimental results, assuming them to have the same variance.

EPMA. The graphite surface is coated by a thin layer of cubic silicon carbide (3C:SiC), and some tiny droplets of silicon $(50 \mu \mathrm{m}$ size $)$ are also found.

The total weight losses, as total $\mathrm{CO}(\mathrm{g})$ and $\mathrm{SiO}(\mathrm{g})$, are shown in Table II. The table does not distinguish between the two quartz types because they have almost the same weight losses. High weight losses are caused by the absence of an outer zone for the $\mathrm{SiO}$ recovery. ${ }^{[32]}$ Weight losses are dependent on the raw material ratio according to the stoichiometry, and higher weight losses are found with pellets.

A total phase mass balance between phases in input and output has been calculated and described in Reference30. The phase mass balance is shown in Figure 8 . The mass balance is written in moles of single phases. Graphite from the crucible participates in the reactions, but only the fraction that has actually reacted with the charge is shown in the balance. The graphite reacts to form $3 \mathrm{C}: \mathrm{SiC}$. Approximately the same amount of $3 \mathrm{C}: \mathrm{SiC}$ is formed in all the experiments. More $\mathrm{SiO}(\mathrm{g})$ is formed and more $\mathrm{SiC}$ has reacted for molar ratio $\mathrm{SiO}_{2}: \mathrm{SiC}=1: 2$. Almost no quartz was left in the experiments with pellets.

An equilibrium phase diagram for different initial molar ratios $\mathrm{SiC}: \mathrm{SiO}_{2}$ and under the condition of total pressure $0.1 \mathrm{~atm}\left(10^{4} \mathrm{~Pa}\right)$ is shown in Figure 9. The diagram shows the stable equilibrium phases during heating of a charge mixture for different initial molar ratios $\mathrm{SiC}: \mathrm{SiO}_{2}$. The equilibrium simulation describes an experimental situation where a mixture of $\mathrm{SiO}_{2}-\mathrm{SiC}$ is brought to a certain temperature in a crucible surrounded by inert gas. The system reacts and diffusion in the crucible makes the gas composition equal at the top and in the pores between the particles. Because the equilibrium pressure of the system is higher than the gas outside the crucible, the gas flows out through the lid. The equilibrium calculations refer to a total pressure equal to $0.1 \mathrm{~atm}\left(10^{4} \mathrm{~Pa}\right)$ (where $\mathrm{P}_{\mathrm{CO}}+\mathrm{P}_{\mathrm{SiO}}=0.1 \mathrm{~atm}$ and $\left.\mathrm{P}_{\mathrm{CO}}+\mathrm{P}_{\mathrm{SiO}}+\mathrm{P}_{\mathrm{Ar}}=1 \mathrm{~atm}\right)$. Because argon is inert, only $\mathrm{P}_{\mathrm{CO}}$ and $\mathrm{P}_{\mathrm{SiO}}$ influenced the chemical equilibrium. When a mixture of silica and silicon carbide of molar ratio $\mathrm{SiO}_{2}: \mathrm{SiC}=1: 1$ is heated up to $2273 \mathrm{~K}$ $\left(2000{ }^{\circ} \mathrm{C}\right)$, the stable solid phase is $\mathrm{Si}$ according to the equilibrium phase diagram. If the amount of $\mathrm{SiC}$ in the charge mix is increased, both $\mathrm{SiC}$ and $\mathrm{Si}$ become stable phases. These conditions are represented by the two points marked in Figure 9. Although the experiments are not run at equilibrium conditions, more $\mathrm{SiC}$ was left in a charge mix richer in $\mathrm{SiC}$, in agreement with the stable phases predicted by the phase diagram.

Figure 10 shows the total $\mathrm{SiO}(\mathrm{g})$ production. The total $\mathrm{SiO}(\mathrm{g})$ has three components: $\mathrm{SiO}(\mathrm{g})$ lost out from the crucible, denoted $\mathrm{SiO}_{\text {lost }} ; \mathrm{SiO}(\mathrm{g})$ that has reacted with the graphite crucible to form 3C:SiC, denoted $\mathrm{SiO}_{3 \mathrm{C}: \mathrm{SiC}}$; and $\mathrm{SiO}(\mathrm{g})$ that has reacted with $\mathrm{SiC}$ to form $\mathrm{Si}$, denoted $\mathrm{SiO}_{\mathrm{Si}}$. These values have been calculated from Eqs. [9] through [11], respectively, and are normalized on the initial amount of silica and silicon carbide. Note that the normalized fraction of $\mathrm{SiO}(\mathrm{g})$ that has reacted to produce $\mathrm{Si}$ is the silicon yield. Figure 10 shows that more $\mathrm{SiO}(\mathrm{g})$ is produced and lost and less silicon is produced when pellets are used as charge material. The parameters $z, a, b, c, u$, and $p$ are the coefficients in Eq. [8].

$$
\mathrm{SiO}_{\text {lost }}=\frac{z}{a+b+c}
$$




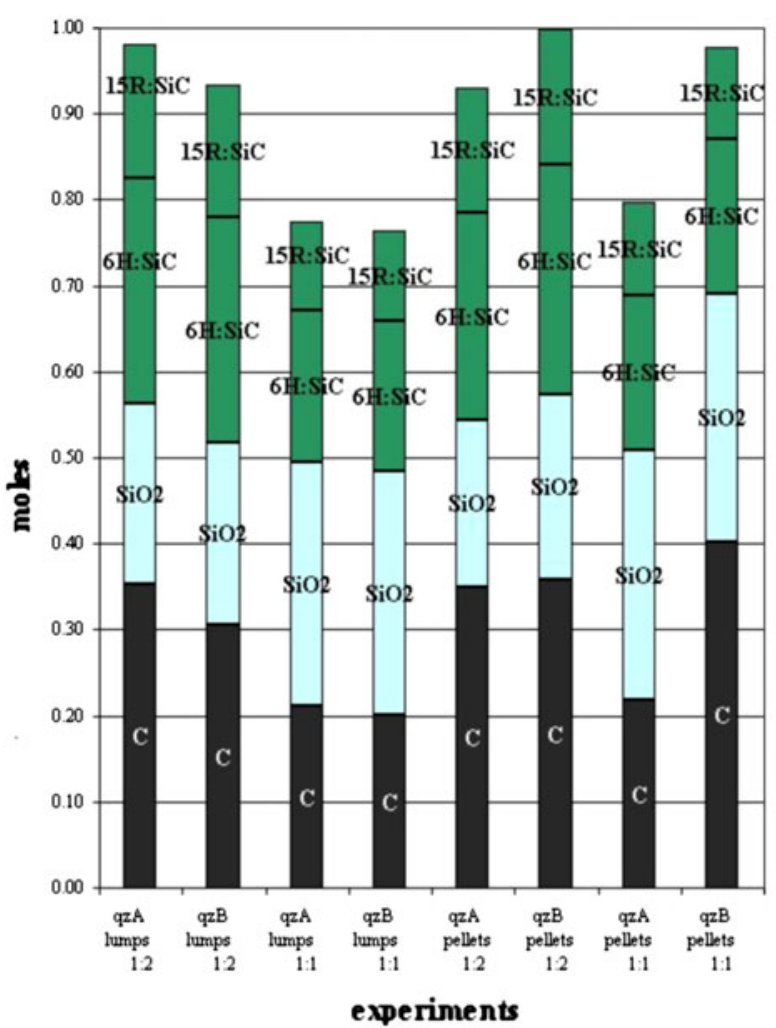

(a)

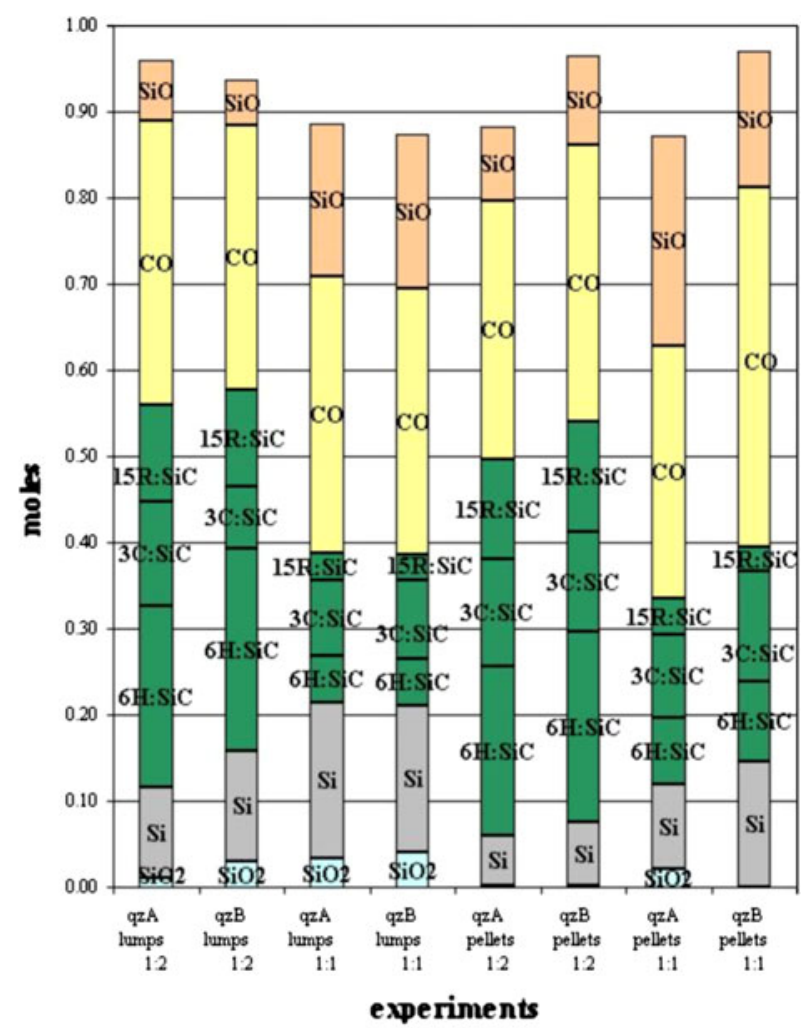

(b)

Fig. 8 - (a) Reactants (in moles) for each experimental run; (b) Reaction products and nonreacted charge (in moles) for each experimental run.

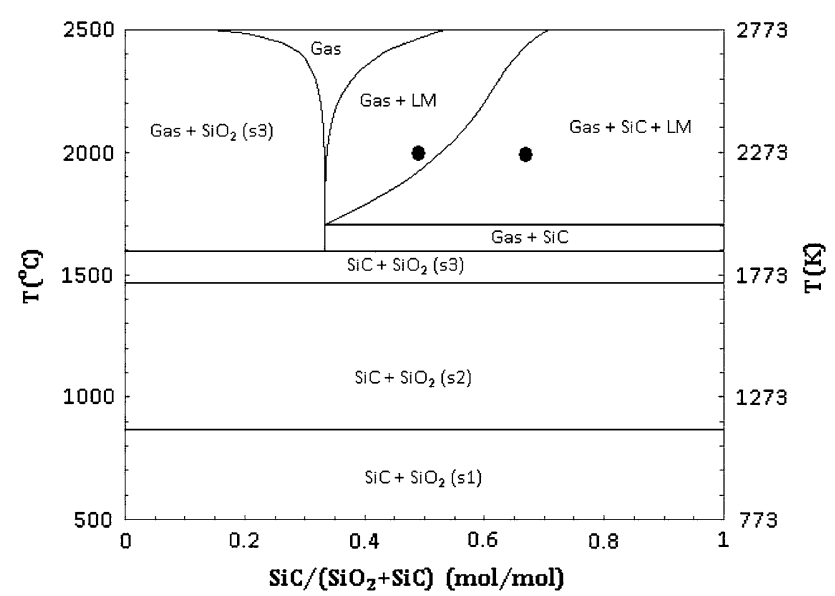

Fig. 9-Equilibrium phase diagram: temperature $\left[{ }^{\circ} \mathrm{C}\right]$ vs charge molar ratio. "Gas ideal" refers to the gaseous phase and is mainly composed by $\overline{\mathrm{SiO}}$ and $\mathrm{CO}$, "LM" stands for liquid silicon, and " $\mathrm{SiO}_{2}$ " stands for the four different silica polymorphs occurring during heating.

$$
\begin{gathered}
\mathrm{SiO}_{3 \mathrm{C}: \mathrm{SiC}}=\frac{u}{a+b+c} \\
\mathrm{SiO}_{\mathrm{Si}}=\frac{p}{a+b+c}
\end{gathered}
$$

The silicon yield is plotted in Figure 11. It has been calculated as the fraction between the number of moles

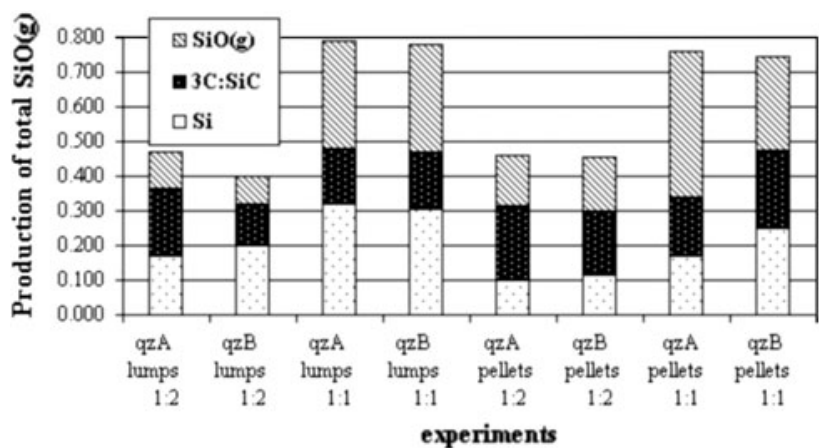

Fig. 10-Three components of the total $\mathrm{SiO}(\mathrm{g})$ produced in the experiments: $\mathrm{SiO}$ lost out of the crucible, $\mathrm{SiO}$ reacted with the graphite crucible to form $3 \mathrm{C}: \mathrm{SiC}$, and $\mathrm{SiO}$ reacted with $\mathrm{SiC}$ to form $\mathrm{Si}$. The values are normalized on the initial amount (in moles) of the $\mathrm{SiC}$ and $\mathrm{SiO}_{2}$ charge.

of $\mathrm{Si}$ produced and the number of moles of $\mathrm{SiC}$ and $\mathrm{SiO}_{2}$ in the charge (Eq. [11]). Higher silicon yield is obtained when lumpy charge is used. Low silicon yield is a consequence of the high $\mathrm{SiO}(\mathrm{g})$ losses during the experiment.

Figure 12 shows the amount of reacted $6 \mathrm{H}: \mathrm{SiC}$ and 15R:SiC polymorphs with silica. The values are normalized on the total amount of $\mathrm{SiC}$ charge material according to Eqs. [12] and [13]. Generally, $6 \mathrm{H}: \mathrm{SiC}$ shows higher reactivity to $\mathrm{SiO}(\mathrm{g})$ than 15R:SiC with the exception of experiment "qzB lumps 1:2." 


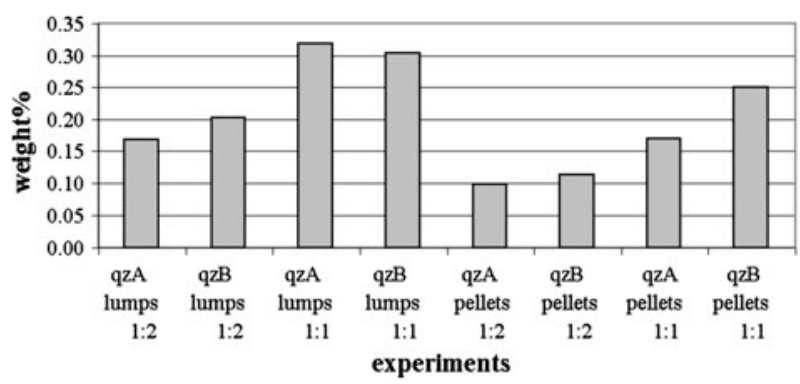

Fig. 11-Si yield for each experimental condition.

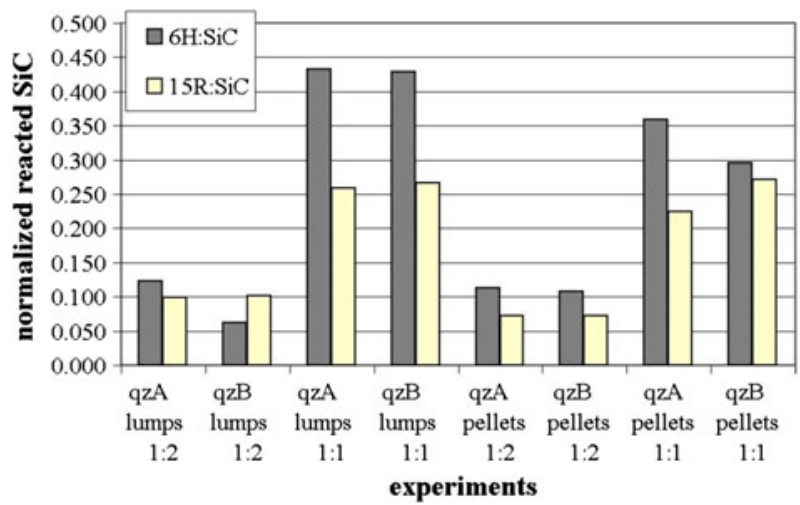

Fig. 12-Moles of reacted $6 \mathrm{H}: \mathrm{SiC}$ and $15 \mathrm{R}: \mathrm{SiC}$ polytypes normalized on the moles of $\mathrm{SiC}$ input.

$$
\begin{gathered}
6 \mathrm{H}: \mathrm{SiC}_{\text {reacted }}=\frac{c-t}{b+c} \\
15 \mathrm{R}: \mathrm{SiC}_{\text {reacted }}=\frac{b-s}{b+c}
\end{gathered}
$$

\section{B. Thermal Properties of Silica}

The melting point was defined as the temperature when the silica surface becomes glassy. Quartz A has a melting point of $2053 \mathrm{~K} \pm 18 \mathrm{~K}\left(1780{ }^{\circ} \mathrm{C} \pm 18{ }^{\circ} \mathrm{C}\right)$, whereas quartz B melted at $2092 \mathrm{~K} \pm 19 \mathrm{~K}$ $\left(1819{ }^{\circ} \mathrm{C} \pm 19{ }^{\circ} \mathrm{C}\right)$. It was a challenge to measure the melting temperature for some of the quartz A samples because they did not turn transparent during heating but presented only a whitish appearance. The samples were examined by optical microscopy after the experiment, and it was found that the whitish samples contained larger amount of bubbles. The diffraction of light through these bubbles can explain the whitish appearance of the samples. The experiments were stopped at temperatures between the silica melting temperature and $2273 \mathrm{~K}\left(2000^{\circ} \mathrm{C}\right)$, and the weight losses were measured. Figure 13 shows weight losses vs time. The weight losses depend on the reactivity of silica in $\mathrm{CO}$ atmosphere. According to reaction [6], $\mathrm{SiO}_{2}$ reacts with $\mathrm{CO}(\mathrm{g})$ and $\mathrm{SiO}(\mathrm{g}), \mathrm{CO}_{2}(\mathrm{~g})$ are produced at high $\mathrm{P}_{\mathrm{CO}}$. The more $\mathrm{SiO}(\mathrm{g})$ is produced, the larger the weight losses.

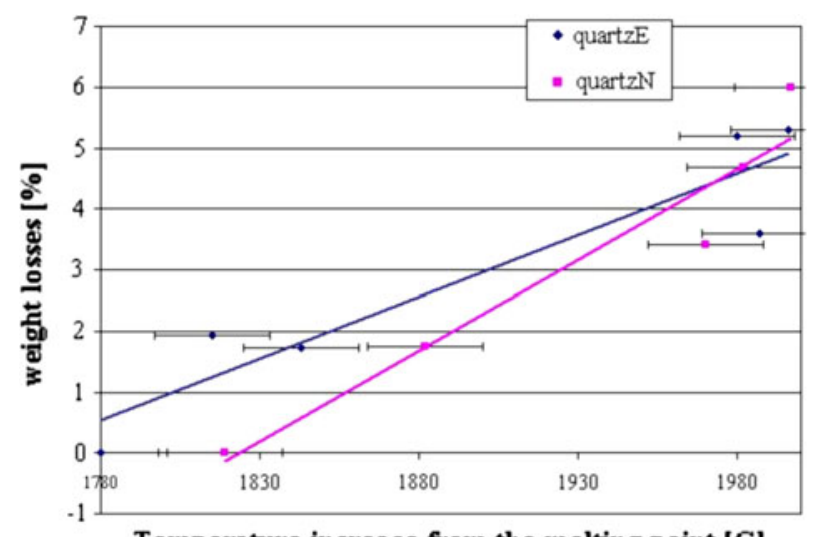

Temperature increase from the melting point $[\mathrm{C}]$

Fig. 13-Silica weight losses [pct] vs temperature $\left[{ }^{\circ} \mathrm{C}\right]$.

\section{DISCUSSION}

\section{A. Difference Between Pellets and Lumps: Reaction Mechanisms}

The images of the reacted charge and the calculated $\mathrm{SiO}(\mathrm{g})$ total production (Figures 6, 7, and 10) make it possible to suggest the predominant reactions when pellets or lumps of $\mathrm{SiO}_{2}$ and $\mathrm{SiC}$ are heated up to $2273 \mathrm{~K}\left(2000{ }^{\circ} \mathrm{C}\right)$.

At the beginning, $\mathrm{SiO}(\mathrm{g})$ is produced and reacts with the graphite crucible to form $3 \mathrm{C}: \mathrm{SiC}$. As the $\mathrm{SiC}$ layer on the inner surface of the crucible builds up, the reaction slows down and the $\mathrm{SiC}$ forming reaction stops. A slightly greater amount of $3 \mathrm{C}: \mathrm{SiC}$ has been formed with pellet charge probably because of the larger production of $\mathrm{SiO}(\mathrm{g})$. Three reactions involving silica and silicon carbide take place: reaction [1] between $\mathrm{SiO}_{2}(1, \mathrm{~s})$ and $\mathrm{SiC}(\mathrm{s})$, reaction [2] between $\mathrm{SiO}(\mathrm{g})$ and $\mathrm{SiC}(\mathrm{s})$, and reaction [3] between $\mathrm{SiO}_{2}(\mathrm{l})$ and $\mathrm{Si}(1)$.

\section{Reaction (1) between $\mathrm{SiO}_{2}$ and $\mathrm{SiC}$}

The reaction is expected to be faster in presence of molten $\mathrm{SiO}_{2}{ }^{[28,33]}$ and for the case of pellets because of the larger surface area available and closer contact between the reactants in the charge mixture. More $\mathrm{SiO}_{2}$ is expected to react with $\mathrm{SiC}$ in pellets for the same reason. This was confirmed by the calculated mass balance. The estimated nonreacted silica was on average 2 wt pct for the case of lumpy charge and on average only $0.18 \mathrm{wt}$ pct for the case of pellets.

\section{Reaction (2) between $\mathrm{SiO}$ and $\mathrm{SiC}$}

As the $\mathrm{P}_{\mathrm{SiO}}$ increases, the reaction between $\mathrm{SiO}(\mathrm{g})$ and $\mathrm{SiC}$ takes place and $\mathrm{Si}$ is produced. The pellets and the $\mathrm{SiC}$ particles inside the pellets decreased in size as the reduction proceeds. The silicon production reaction when pellets are used takes place inside the pellets and mostly in the rim zone (Figure 6(b)). The more favorable Si formation at pellets rim might be pressure related. Larger zones of silicon occur with lumpy charge. This is probably because of several Si-forming reactions that occur simultaneously in the lumpy charge. Si forms on the $\mathrm{SiC}$ surface in $\mathrm{SiC}$ pores and concave surfaces according to reaction [2]. Once the silicon has covered 
the available $\mathrm{SiC}$ surface, instead of reaction [2], a coupled reaction between $\mathrm{SiC}$ and $\mathrm{Si}(1)$ and between dissolved carbon in $\mathrm{Si}(1)$ and $\mathrm{SiO}$ may take place. $\mathrm{Si}$ grows inward both the $\mathrm{SiC}$ particle and the molten silica. $\mathrm{SiC}$ at higher temperatures may dissolve in $\mathrm{Si}$. Dissolved carbon diffuses to the surface of the Si droplets, reacts with $\mathrm{SiO}(\mathrm{g})$, and forms $\mathrm{Si}$. The carbon solubility in liquid silicon at $2073 \mathrm{~K}$ and $2273 \mathrm{~K}\left(1800{ }^{\circ} \mathrm{C}\right.$ and $\left.2000{ }^{\circ} \mathrm{C}\right)$ is 500 ppmw and 2100 ppmw, respectively. ${ }^{[34]}$ The proposed reactions are described by Eqs. [14] and [15].

When the $\mathrm{Si}$ droplets become coarser, the Si-SiC surface tension can no longer sustain the liquid $\mathrm{Si}$ droplets, and the Si starts dripping toward the bottom of the crucible. Free SiC surface is available for further reactions, $\mathrm{SiC}$ particles are consumed and decrease in size as the reduction proceeds. Another explanation for the larger amount of silicon formed with lumps may be that in lumps more non-reacted silica is available to react to $\mathrm{Si}$ before reaching the chemical equilibrium.

$$
\begin{aligned}
& \mathrm{SiC}_{(\mathrm{s})}+\mathrm{Si}_{(1)}=2 \mathrm{Si}_{(1)}+\underline{\mathrm{C}} \\
& \underline{\mathrm{C}}+\mathrm{SiO}_{(\mathrm{g})}=\mathrm{Si}_{(1)}+\mathrm{CO}_{(\mathrm{g})}
\end{aligned}
$$

\section{Reaction (3) between $\mathrm{SiO}_{2}$ and $\mathrm{Si}$}

When lumpy charge was used, melted quartz and silicon were found on the bottom of the crucibles. The reaction between $\mathrm{SiO}_{2}(1)$ and $\mathrm{Si}(1)$ is expected to take place at high temperatures after some silicon has been produced. Because for the case of pellets, no quartz was left after the experiments and, as mentioned previously, $\mathrm{SiO}_{2}$ seems to react quickly to $\mathrm{SiO}(\mathrm{g})$ before any $\mathrm{Si}(1)$ is produced, the reaction between $\mathrm{SiO}_{2}$ and $\mathrm{Si}(1)$ seems to be negligible in the pellet charge.

\section{B. Difference Between Pellets and Lumps: $\mathrm{SiO}$ Production}

More $\mathrm{SiO}(\mathrm{g})$ has been produced with pellets. The particles in the pellets are in close contact so that the diffusion of $\mathrm{CO}_{2}$ from the $\mathrm{SiO}_{2}$ particle to the $\mathrm{SiC}$ particle and the diffusion of $\mathrm{CO}$ from the $\mathrm{SiC}$ particle to the $\mathrm{SiO}_{2}$ particles are enhanced. Moreover, because the quartz powder has been milled, the silica surface is mechanically activated, which leads to an increase in the extent of adsorption and gas diffusion into the disturbed near surface layers. ${ }^{[22-25]}$

The experiments aim at reproducing the hot inner zone of a furnace. From the total mass balance, it is possible to write the overall reaction representative of the inner crater zone. The overall reaction for the experimental condition "lumps qzN 1:1" is given in Eq. [16]. The overall reaction for the eight representative experiments differ from reaction [4]; the calculated equilibrium reaction of the inner zone at $1 \mathrm{~atm}$ $\left(10^{5} \mathrm{~Pa}\right)$ and at $2273 \mathrm{~K}\left(2000{ }^{\circ} \mathrm{C}\right)$.

$$
\begin{aligned}
& 0.28 \mathrm{SiO}_{2}+0.28 \mathrm{SiC}+0.2 \mathrm{C} \\
& =0.17 \mathrm{Si}+0.04 \mathrm{SiO}_{2}+0.17 \mathrm{SiC} \\
& \quad+0.17 \mathrm{SiO}+0.30 \mathrm{CO}
\end{aligned}
$$

The reactions depart from equilibrium and the $\mathrm{SiO}(\mathrm{g})$ content of the gas in the crucible is determined by the reaction kinetics. The parameter $s$ is defined in Eq. [17] as the equilibrium fraction of $\mathrm{SiO}(\mathrm{g})$ that leaves the silicon-producing zone. The parameter $s$ is variable but is here assumed constant for certain combination of raw materials and operation conditions. ${ }^{[14,35]}$ The lower the $s$ value, the less $\mathrm{SiO}(\mathrm{g})$ leaves the silicon-producing zone and the slower the reaction rate.

$$
s=\frac{\mathrm{P}_{\mathrm{SiO}}}{\mathrm{P}_{\mathrm{SiO}}+\mathrm{P}_{\mathrm{CO}}}
$$

The $s$ value can be estimated from the $\mathrm{CO}$ and $\mathrm{SiO}$ coefficients in the overall reaction in Eq. [8]. During the initial heating, low-temperature reactions occur and the partial pressure of $\mathrm{CO}(\mathrm{g})$ and $\mathrm{SiO}(\mathrm{g})$ are different from the ones occurring at higher temperatures. For this reason, the amount of $\mathrm{CO}(\mathrm{g})$ and $\mathrm{SiO}(\mathrm{g})$ calculated from the mass balance are not representative of the inner zone and should not be used to estimate the $s$ value. Two tentative $s$ values have been calculated and are shown in Figure 14. The figure refers to the experiments run with quartz B. The first calculation uses the total moles of $\mathrm{CO}(\mathrm{g})$ and $\mathrm{SiO}(\mathrm{g})$ calculated from the mass balance. This value is expected to be low because it includes the fraction of $\mathrm{SiO}(\mathrm{g})$ and $\mathrm{CO}(\mathrm{g})$ produced during the initial heating at low $\mathrm{P}_{\mathrm{SiO}}$ atmosphere. The second calculation uses the same value of $\mathrm{SiO}(\mathrm{g})$ but decreases $\mathrm{CO}(\mathrm{g})$ of an amount corresponding to the production of $3 \mathrm{C}: \mathrm{SiC}$ in the crucible. The two $s$ values have the same trend: $s$ is dependent on the mix ratio and charge size, and $s$ increases by increasing the amount of $\mathrm{SiO}_{2}$ in the charge mix. The dependence on the reactant ratio is even stronger for the case of lumps. A possible reason might be that $\mathrm{Si}$ reacts with the remaining $\mathrm{SiO}_{2}$ to form $\mathrm{SiO}(\mathrm{g})$ when lumpy charge is used.

With pellets materials, there is a bigger amount of $\mathrm{SiO}(\mathrm{g})$ leaving the high-temperature zone. In industrial practice, the $\mathrm{SiO}(\mathrm{g})$ is recovered in the upper part of the furnace by reaction with carbon that is a strongly heatconsuming reaction. Then, the gas is cooled and the

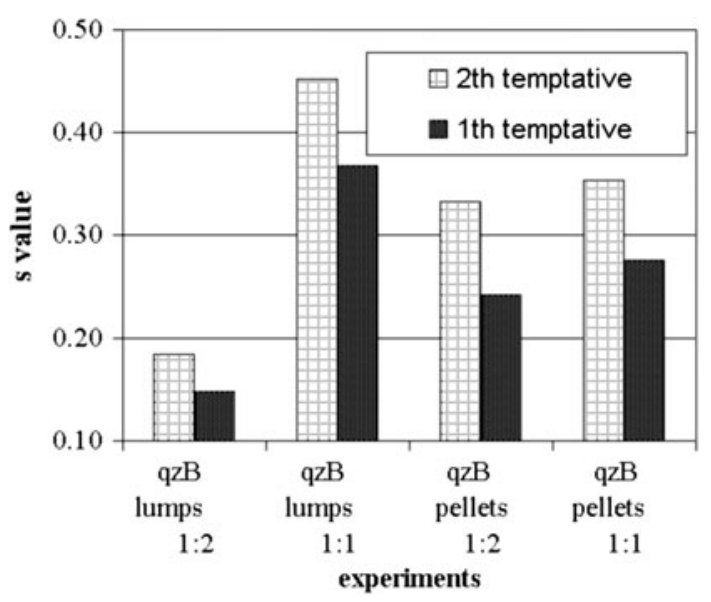

Fig. 14 Calculated $s$ value for the same quartz type and different charge mix and size. 
heat-producing condensation reaction takes place. The produced heat will raise the temperature of the charge, and again, the strongly heat consuming reaction takes place. However, the price of the increased silicon recovery is a high load of condensed $\mathrm{SiO}$ that may obstruct the gas flow and make stoking difficult and inefficient. ${ }^{[15]}$

\section{Effect of Raw Material Mixtures}

The reactivity of different quartz and silicon carbide sources has been studied. The $\mathrm{SiC}$ charge material is a mixture of hexagonal and rhombohedral polytypes. In contrast with Filsinger and Bourrie ${ }^{[10]}$ and Presser and Nickel, ${ }^{[21]}$ the two polytypes show different reactivity with silica (Figure 12). Hexagonal silicon carbide $6 \mathrm{H}: \mathrm{SiC}$ is more reactive than the rhombohedral 15R:SiC for all the experiments. All polytypes have the same distance between neighboring $\mathrm{Si}$ or $\mathrm{C}$ atoms, and same distance of the $\mathrm{C}$ atom to each of the $\mathrm{Si}$ atoms. The only difference between them is the degree of hexagonality, which is defined as the ratio of number of atoms at hexagonal sites to the total number of atoms per unit cell. ${ }^{[36]} 6 \mathrm{H}: \mathrm{SiC}$ has degree of hexagonality 0.33 , whereas 15R:SiC has a 0.4 degree of hexagonality. The degree of hexagonality seems to influence the $\mathrm{SiC}$ reactivity: The lower the degree of hexagonality, the better the reactivity.

The reactivity of different hydrothermal vein quartzes has been studied in two experimental setups: the sessile drop furnace and induction furnace. The reactivity of $\mathrm{SiO}_{2}$ is measured as the amount of $\mathrm{SiO}(\mathrm{g})$ produced. Silica reacts with $\mathrm{CO}(\mathrm{g})$ and it forms $\mathrm{SiO}(\mathrm{g})$ and $\mathrm{CO}_{2}(\mathrm{~g})$, both in presence of high and low $\mathrm{P}_{\mathrm{SiO}}$. In particular, on the one hand, the experiments in the sessile drop furnace were run in $\mathrm{CO}(\mathrm{g})$ atmosphere and were significant for reaction [6] occurring at high $\mathrm{P}_{\mathrm{CO}}$ pressure. On the other hand, the reactions in the induction furnace take place both at high and low $\mathrm{P}_{\mathrm{CO}}$ and the total amount of $\mathrm{SiO}(\mathrm{g})$ formed is also caused by the reaction of $\mathrm{SiC}$ with $\mathrm{CO}_{2}(\mathrm{~g})$. Because the same $\mathrm{SiC}$ has been used for all the experiments, we can assume $\mathrm{SiO}_{2}$ as the only source for difference in the amount of $\mathrm{SiO}(\mathrm{g})$ produced. The experiments in the sessile drop furnace show higher reactivity for quartz A (Figure 13), which has been confirmed by the carbothermic reduction experiments (Figure 10). This study shows that the reactivity of quartz depends on the silica source used. The higher reaction rate in quartz $\mathrm{A}$ might be caused by the larger amount of fluid inclusions. Fluid inclusions contain gaseous and liquid compounds. When the quartz is heated, the fluid inclusions are opened and might induce cracks. The cracks increase the surface available for further reactions.

The two quartz types present different melting points. Quartz A has slightly lower melting point than quartz B. A higher melting point quartz is preferable because softened and melted silica on the upper part of the furnace obstruct the gas flow. Melted quartz A presents larger amount of bubbles than melted quartz B. Quartz A may also be more reactive because of the presence of bubbles that increase the available surface. The formation of bubbles can be correlated to the presence of fluid inclusions or to the dehydration reaction of mica minerals taking place at calcination temperatures lower than the melting point of silica, ${ }^{[37]}$ or it may be a result of the production of $\mathrm{SiO}(\mathrm{g})$. Microscopy investigation prior to melting revealed a larger amount of microcracks and fluid inclusions in quartz A. Mica was found in both quartz sources.

\section{CONCLUSIONS}

Experiments reproducing the inner zone of a furnace have been performed in an induction furnace. Silica and silicon carbide have been charged as lumps and pellets for different molar ratio. The reaction behavior of lumps and pellets was studied in terms of qualitative and quantitative analysis of the reacted phases.

The main conclusions that can be drawn from the present work are as follows:

1. The reactions in pellets take place inside the pellets mostly in the rim zone, whereas the reactions in lumps occur on the outside. Larger zones of singlephase silicon have been found when a lumpy charge is used. A cavity is present when lumpy charge is used, whereas for the case of pellets, the reacted charge is porous and compacted.

2. More $\mathrm{SiO}(\mathrm{g})$ is produced and almost no quartz is left when pellets are used as charge material for the same molar ratio. Lumps are characterized by a higher silicon yield because of less loss of $\mathrm{SiO}(\mathrm{g})$.

3. Different $\mathrm{SiC}$ polytypes have been used as charge materials. The polytype with lower degree of hexagonal $\mathrm{SiC}$ content has a higher reactivity in terms of reaction rate.

4. Two different hydrothermal vein quartzes have been used as charge materials. The quartz containing more fluid inclusions and more microcracks has lower melting point and better reactivity in terms of reaction rate with $\mathrm{SiO}(\mathrm{g})$.

5. The thermal properties and reactivities of the two quartzes have also been investigated in a sessile drop furnace, and the results from investigation done in the silicon production experiments were confirmed.

\section{OPEN ACCESS}

This article is distributed under the terms of the Creative Commons Attribution Noncommercial License which permits any noncommercial use, distribution, and reproduction in any medium, provided the original author(s) and source are credited.

\section{REFERENCES}

1. M.J. de Wild-Scholten, R. Glockner, J.-O. Odden, G. Halvorsen, and R. Tronstad: 23rd European Photovoltaic Solar Energy Conf., Valencia, Spain, 2008. 
2. R. Kvande, L. Nygaard, S. Stute, and P.C.P. Bronsveld: 25th European Photovoltaic Solar Energy Conference and Exhibition/Conference on Photovoltaic Energy Conversion, Valencia, Spain, 2010.

3. K. Aasly: Ph.D. Dissertation, Norwegian University, Trondheim, Norway, 2008.

4. B. Strake, F.W. Schulze, and H.A. Aulich: Erzmetall, 1988, vol. 41 , p. 126.

5. H.A. Aulich, H.-P. Urbach, F.W. Schulze, and J.G. Grabmaie: Siemens Forsch.-u Entwickl.-Ber. Bd, 1982, vol. 11, p. 327.

6. J.K. Tuset and O. Raaness: Electric Furnace Proceedings, 1976, p. 101.

7. O. Raaness, L. Kolbeinsen, and A. Byberg: 8th International Ferroalloys Congress (INFACON8) Proceedings, Beijing, China, 1998, p. 116.

8. K. Gjermundsen, O. Raaness, and J. Kr. Tuset: SINTEF Selskapet for Industriell Og Teknisk Forskning Ved Norges Tekniske Hogskole, Trondheim, Norway, 1972.

9. P. Motavalli, T. Marler, F. Cruz, and J. McConnell: Essential Plant Nutrients, College of Agriculture and Life Sciences, University of Guam, http://www.cartage.org.lb/en/themes/Sciences/ BotanicalSciences/PlantHormones/EssentialPlant/EssentialPlant. htm.

10. D.H. Filsinger and D.B. Bourrie: J. Am. Ceram. Soc., 1990, vol. 73, p. 1726.

11. M. Hirasawa: High Temp. Mater. Process, 2000, vol. 19, p. 281.

12. K. Wiik: Kinetics of Reactions Between Silica and Carbon, NTH Universiteti, Trondheim Norway, 1990.

13. F. Danes, E. Saint-Aman, and L. Coudurier: J. Mater. Sci, 1993, vol. 28, pp. 489-95.

14. A. Schei, J.K. Tuset, and H. Tvei: Production of High Silicon Alloys, Tapir Forlag, Trondheim Norway, 1998.

15. A. Schei: Tidsskr. Kjemi Bergv., 1967, vol. 27, pp. 152-58.

16. M.B. Müller: Scand. J. Metall., 1972, vol. 1, p. 145.

17. R.J. Fruehan and B. Ozturk: Metall. Trans. B, 1985, vol. 16B, p. 801.

18. V. Sahajwalla, C. Wu, R. Khanna, N.S. Chaudhury, and J. Spink: ISIJ Int., 2003, vol. 43, p. 1309.
19. A.W. Weimer, K.J. Nilsen, G.A. Cochran, and R.P. Roach: AIChE Journal, 1993, vol. 39, p. 409.

20. M.V. Chase, Jr: JANAF Thermochemical Tables, C.A. Davies, J.R. Downey, Jr., D.J. Frurip, R.A. Macdonald, and A. Syverud, eds., Bureau of Standards, Midland, MI, 1985.

21. V. Presser and K.G. Nickel: Crit. Rev. Solid State Mater. Sci., 2008, vol. 33, p. 1.

22. W. Peukert and C. Damn: Langmuir, 2009, vol. 25, p. 2264.

23. U. Steinike and K. Tkáčová: J. Mater. Synth. Process., 2000, vol. 8, p. 197.

24. V. Balek, J. Fusek, J. Križ, and M. Murat: Thermochim. Acta, 1988, vol. 262, p. 209.

25. J.C. Benezet and A. Benhassaine: Erzmetall, 1988, vol. 41, p. 126.

26. A. Agarwal and U. Pad: Metall. Mater. Trans. B, 1998, vol. 30B, pp. 295-306.

27. R. Jensen: Gass-stabilisert AG og DL lysbue i Si-metallovn, NTH Norges Tekniske Høyskole, 1986.

28. V. Andersen: Investigation of Thermal Properties of Quartz for the Silicon Industry Under Reducing Atmosphere, Department of Materials Science and Engineering, NTNU, 2009.

29. N.G. Wright: Kirk-Othmer Encyclopedia of Chemical Technology, University of New Castle Upon Tyme, p. 525.

30. E.D. Martello, G. Tranell, O. Raaness, and L. Arnberg: Combined $X R D$ and XRF Technique for Quantitative Mass Balance of $\mathrm{Si}$ Production Experiments, Norwegian University of Science and Technology, Trondheim, Norway, 2011.

31. Bruker AXS homepage, http://www.bruker-axs.com.

32. Y. Sakaguchi, M. Ishizaki, T. Kawahara, M. Fukai, M. Yoshiyagawa, and F. Aratani: ISIJ Int., 1992, vol. 32, p. 643.

33. V. Andersen: Master Thesis, NTNU, Trondheim, Norway, 2010.

34. R.I. Scace and G.A. Slack: J. Chem. Phys., 1958, vol. 30, p. 1551.

35. A. Schei and K. Larsen: 39th Electric Furnace Conference of AIME. Houston, TX, 1981.

36. A.A. Lebedev: Am. Inst. Phys., 1999, vol. 33, p. 707.

37. B.-Z. Zhu, Y.-L. Sun, and C.-W. Xie: J. China Coal Soc., 2008, p. 1049. 